\title{
Numerical simulation and experimental investigation of laser overlap welding of Ti6Al4V and 42CrMo
}

\author{
Shusen Zhao, Gang Yu*, Xiuli He, Yongjie Zhang, Weijian Ning \\ Key Lab of Mechanics in Advanced Manufacturing, Institute of Mechanics, Chinese Academy of Sciences, 15 Beisihuanxi Road, Beijing 100190, People's Republic of China
}

\section{A R T I C L E I N F O}

\section{Article history:}

Received 30 June 2010

Received in revised form

12 November 2010

Accepted 16 November 2010

\section{Keywords:}

Laser overlap welding

Heat transfer model

Titanium alloy

Alloy steel

Intermetallic compounds

\begin{abstract}
A B S T R A C T
Finite element method (FEM) and processing experiments were utilized to investigate the thermal phenomena and microstructure of laser overlap welding of Ti6Al4V and 42CrMo. A FEM model of temperature field was established, under considerations of thermal contact resistance and forced convection effect of shielding gas flow. Based on the model, temperature field with various laser power values and scanning velocities was calculated to explore the relationship between the process parameters and the interface temperature. Experiments were conducted on a $1 \mathrm{~kW} \mathrm{Nd:YAG} \mathrm{laser} \mathrm{materials} \mathrm{processing} \mathrm{system} \mathrm{with}$ five-axis CNC working station. Microstructure, chemical composition and microhardness of the joint were evaluated. From the numerical simulation and experimental investigation, the calculated temperature history at measuring points had the similar tendency to the experimental results. The interface temperature could just reach or be a little higher than the melting point of the lower sheet material $42 \mathrm{CrMo}$ by adjusting the process parameters according to the numerical calculation. At the interface, intermetallic compounds TiFe and $\mathrm{TiFe}_{2}$ were detected. The thickness of intermetallic reaction layer containing intermetallic compounds was found to depend on the heat input.
\end{abstract}

(C) 2010 Elsevier B.V. All rights reserved.

\section{Introduction}

Turbo disk and turbo shaft of turbo-compressor rotor of some diesel engines, are made of titanium alloy and alloy steel, respectively. Therefore, the technology for joining titanium alloys to alloy steel is required for manufacturing engine turbo components.

Some research for joining of titanium alloys and steels has been carried out. Li et al. (2006) reported vacuum brazing of titanium-aluminum alloy and alloy steel using $\mathrm{Ag}-\mathrm{Cu} / \mathrm{Ti} / \mathrm{Ag}-\mathrm{Cu}$ filler metal, the author referred to the presence of intermetallic compounds in the reaction layer that weakened the mechanical properties of the joint. Shiue et al. (2008) studied the infrared brazing of Ti-6Al-4V and 17-4 PH stainless steel using two silverbased braze alloys with $(\mathrm{Ni}) / \mathrm{Cr}$ barrier layer(s) and referred to the inhibition of the interfacial reaction between the 17-4PH SS and the molten braze during brazing. Ghosh et al. (2003) used solid-state diffusion bonding to produce transition joints between Ti-5.5Al-2.4V and stainless steel 304. Sheng et al. (2005) applied phase transformation superplastic diffusion bonding between titanium alloy and stainless steel. It was shown that both the brittle intermetallic compound (FeTi) and the $\beta$-Ti based solid solution were formed on the tensile fracture interface. Atasoy and Kahraman

\footnotetext{
* Corresponding author at: Building 2, Room 205, 15 Beisihuanxi Road, Beijing 100190, People's Republic of China. Tel.: +86 010 82544250; fax: +86 01082544250

E-mail addresses: zhaoshusen@imech.ac.cn (S. Zhao), gyu@imech.ac.cn (G. Yu).
}

(2008) studied the diffusion bonding of commercially pure titanium and low carbon steel using a silver interlayer at various temperatures for various diffusion times. Kundu et al. (2005) and Kundu and Chatterjee (2008) presented the diffusion bonding between pure titanium and stainless steel 304 with different metal interlayer such as copper interlayer and nickel. Kahraman et al. (2005) studied explosive welding of stainless steel and titanium plates. From their experimental research mentioned above, solid state joining is a feasible method to join titanium alloy and steel for the reason that it could restrain the formation of intermetallic compounds in the welding process, but the joining process needs a vacuum chamber and has low efficiency. The prospect of totally encompassing huge components in a vacuum canopy is not practicable. Explosive welding process is an effective method for producing composite plates but controllability and automation are difficult.

As one of the new joining technologies, laser welding has a number of benefits in comparison with conventional welding techniques. The primary advantages are high efficiency, excellent controllability and the ability to focus laser radiation in a small area producing a high-intensity heat source. Compared to laser butt welding, laser lap/overlap welding could control the temperature and the elements diffusion at the interface effectively. Hiraga et al. (2001) applied a pulse laser lap welding technique to join thin sheets of pure titanium and stainless steel 304. The author discussed the influence of process parameters on the shear strength, but ignored the relationship between temperature field and interface microstructure. Borrisutthekul et al. (2007) studied 
laser welding of steel and aluminum alloy. It was indicated that the thickness of intermetallic reaction layer could be decreased by controlling heat flow during welding process. Moreover, the joining strength increased with decreasing the thickness of intermetallic reaction layer.

With regard to the numerical simulation, an amount of models were proposed to predict temperature distribution for laser welding. Swift-Hook and Gick (1973) formulated the first heat transfer analytical model for continuous laser welding. Mazumder and Steen (1980) developed the first numerical model of the continuous laser welding process. This model considered a three-dimensional heat transfer and implemented the finite difference technique for a Gaussian beam intensity distribution. Lu (1993) calculated the laser induced temperature distribution in substrates with multilayer structures. In that case, the substrates was equivalent to a homogeneous substrate with anisotropic thermal conductivity. Phanikumar et al. $(2001,2004)$ presented a three-dimensional numerical model of heat transfer for laser welding of dissimilar couples of copper-nickel. Chakraborty and Chakraborty (2007) studied the effects of turbulence on momentum, heat, and mass transfer during laser welding dissimilar materials. Fysikopoulos et al. (2009) described an analytical approach for estimating the energy efficiency of laser manufacturing processes. The above brief review indicates that the numerical modeling is an important issue and the results of the analysis are used for developing processing strategies. However, very few stufies are found to consider the contact resistance and forced convection effect of the shielding gas flow in the models.

In order to implement laser overlap welding of titanium alloy and alloy steel, a mathematical model of heat transfer of the welding process was established. In this model, the contact resistance and forced convection effect of the shielding gas flow were considered. Based on the model, the temperature field with different laser power and scanning velocities was estimated to explore the relationship between the process parameters and the interface temperature. After the overlap welding experiments, microstructure, chemical composition and microhardness of the joint, especially the interface of the overlap sheets, were examined to investigate the weldability of laser overlap welding between titanium alloy and alloy steel.

\section{Mathematical modeling}

A mathematical model was used to calculate the temperature field with different process parameters. During laser overlap welding process, Ti6Al4V and 42CrMo sheets were used as upper and lower sheet, respectively.

\subsection{Assumptions}

The comprehensive 3D FEM model to simulate the temperature of the welding process was based on heat conduction. Besides, the following assumptions were made in order to simplify the calculations:

(1) Laser power density was less than $7 \times 10^{5} \mathrm{~W} / \mathrm{cm}^{2}$, the welding mode was conduction welding. Therefore, laser power density was assumed to be distributed in a Gaussian manner at the top surface of the titanium alloy sheet.

(2) The shielding gas flow along the top sheet was assumed to be laminar flow. The temperature and the flow velocity of shielding gas were invariable throughout the entire process.

(3) Thermal physical properties parameters of the welding materials were piecewise linear with temperature.

\subsection{Governing equation}

The heat transfer equation:

$\frac{\partial T}{\partial t}=\frac{\lambda}{\rho c^{*}}\left(\frac{\partial^{2} T}{\partial x^{2}}+\frac{\partial^{2} T}{\partial y^{2}}+\frac{\partial^{2} T}{\partial z^{2}}\right)$

where $\lambda, c^{*}$ and $\rho$ are the thermal conductivity, equivalent specific heat and density of the materials, respectively. It is convenient to regard the latent heat of fusion as a specific heat in the range of phase transition temperature. Thus, the equivalent heat capacity can be formulated as:

$c^{*}= \begin{cases}c_{\mathrm{S}}(T) & T<T_{\mathrm{S}} \\ \frac{c_{\mathrm{S}}(T)+c_{\mathrm{L}}(T)}{2}+\frac{L}{T_{\mathrm{L}}-T_{\mathrm{S}}} & T_{\mathrm{S}} \leq T \leq T_{\mathrm{L}} \\ c_{\mathrm{T}}(T) & T>T_{\mathrm{L}}\end{cases}$

where $T_{\mathrm{S}}$ and $T_{\mathrm{L}}$ are the solidus temperature and liquids temperature, respectively, $c_{S}(T)$ and $c_{\mathrm{L}}(T)$ are the specific heat of solid and liquid dependent on temperature, respectively, and $L$ is the latent heat of fusion.

\subsection{Boundary conditions}

The contact thermal resistance between upper and lower sheets is defined as:

$R_{\mathrm{c}}=\frac{l_{\mathrm{c}}}{\lambda_{\mathrm{c}}}$

where $l_{\mathrm{C}}$ is the characteristic length, taken as the thickness of the contact zone, and $\lambda_{c}$ is the thermal conductivity of the contact zone.

The boundary condition of top surface can be expressed as:

$\lambda \frac{\partial T}{\partial z}=\frac{2 P \eta}{\pi r_{\mathrm{b}}^{2}} \exp \left(-\frac{2\left(x^{2}+y^{2}\right)}{r_{\mathrm{b}}^{2}}\right)-h_{\mathrm{t}}\left(T-T_{\mathrm{a}}\right)-\sigma \varepsilon\left(T-T_{\mathrm{a}}\right)$

Here, $P$ is the laser power, $\eta$ is the laser absorption coefficient, $r_{\mathrm{b}}$ is the effective radius of laser beam, $h_{\mathrm{t}}$ is the convection coefficient of the top surface, $\sigma$ is the Stefan-Boltzmann constant, $\varepsilon$ is the emissivity, and $T_{\mathrm{a}}$ is the ambient temperature.

The convection coefficient of top surface under shielding gas is given by:

$h_{\mathrm{t}}=\frac{\lambda_{\mathrm{g}}}{l} \mathrm{Nu}$

where $\lambda_{\mathrm{g}}$ is the conductivity of the shielding gas, and $l$ is the characteristic length, taken as the width of the welding specimen and $\mathrm{Nu}$ is the Nusselt number. $\mathrm{Nu}$ is defined as:

$N u=0.664(\operatorname{Re})^{1 / 2}(\operatorname{Pr})^{1 / 3}$

where Re and Pr is the Reynolds number and Prandtl number of the shielding gas flow, respectively.

$R e=\frac{\rho_{\mathrm{g}} u_{\mathrm{g}} l}{\mu_{\mathrm{g}}}$

$\operatorname{Pr}=\frac{\mu_{\mathrm{g}} c_{\mathrm{g}}}{\lambda_{\mathrm{g}}}$

where $\rho_{\mathrm{g}}, \mu_{\mathrm{g}}$ and $c_{\mathrm{g}}$ are the density, dynamic viscosity and specific heat of shielding gas, respectively.

The convection coefficient of symmetric surface is given by:

$h_{\mathrm{s}}=0$

On other surfaces, the convection condition is set to be natural convection:

$\lambda \frac{\partial T}{\partial n}=h_{\mathrm{c}}\left(T-T_{\mathrm{a}}\right)$

where $h_{\mathrm{c}}$ is the convection coefficient. 


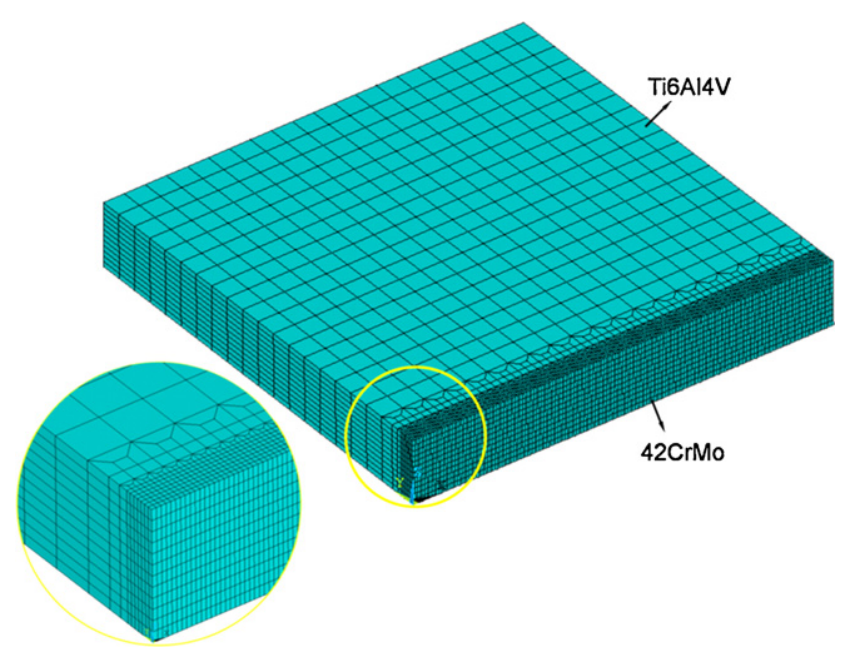

Fig. 1. Finite element mesh.

The initial temperature of the welding material is equal to the ambient temperature:

$T(x, y, z, 0)=T_{\mathrm{a}}$

\subsection{Finite element mesh}

FEM was used to estimate temperature distribution of the specimens in the welding process. As the geometry, boundary conditions and heat source were symmetric, half of the workpieces were chosen for calculation using the commercial program ANSYS. The FEM model was established using two types of elements and shown in Fig. 1, containing three dimensional volume elements SOLID70 with eight nodes and thermal surface effect element SURF152 defined by four nodes from the basic body and an extra node away from the base element. The three dimensional element was used for the basic body structure and the thermal surface effect element for the boundary between the structure and the environment. A denser mesh was used in the area along the weld line, and a coarser mesh for the rest of the structure.

ANSYS software supports thermal contact conduction between two contacting surfaces. Contact elements TARGE170, CONTAC174 were used to simulate the contact of the overlap sheets. The conductive heat transfer between two contacting surfaces is defined as:

$q=T C C \times\left(T_{\mathrm{t}}-T_{\mathrm{C}}\right)$

where $q$ is the heat flux per area, TCC is the thermal contact conductance coefficient, having units of heat/(time $\times$ temperature) for thermal contact conduction and is set to be the reciprocal of contact resistance $R_{\mathrm{c}}$ in the program calculation, and $T_{\mathrm{t}}$ and $T_{\mathrm{c}}$ are the temperature of target surface and contact surface, respectively.

\section{Experimental}

Ti6Al4V and rolled alloy steel $42 \mathrm{CrMo}$ with dimension of $60 \mathrm{~mm} \times 20 \mathrm{~mm} \times 1 \mathrm{~mm}$ and $60 \mathrm{~mm} \times 20 \mathrm{~mm} \times 2 \mathrm{~mm}$ were used in the experiments, respectively. The chemical composition of Ti6Al4V and 42CrMo are given in Table 1 and Table 2, respectively. Oxide layers and contamination were removed from the surfaces of

Table 1

Chemical composition of Ti6Al4V (mass fraction (\%))

\begin{tabular}{lllllllll}
\hline $\mathrm{Al}$ & $\mathrm{V}$ & $\mathrm{Fe}$ & $\mathrm{Si}$ & $\mathrm{C}$ & $\mathrm{N}$ & $\mathrm{H}$ & $\mathrm{O}$ & $\mathrm{Ti}$ \\
\hline $5.5-6.8$ & $3.5-4.5$ & 0.3 & 0.15 & 0.1 & 0.05 & 0.015 & 0.15 & Bal. \\
\hline
\end{tabular}

Table 2

Chemical composition of $42 \mathrm{CrMo}$ (mass fraction (\%)).

\begin{tabular}{llllllll}
\hline $\mathrm{C}$ & $\mathrm{Si}$ & $\mathrm{Mn}$ & $\mathrm{P}$ & $\mathrm{S}$ & $\mathrm{Cr}$ & $\mathrm{Mo}$ & $\mathrm{Fe}$ \\
\hline 0.42 & 0.28 & 0.61 & 0.016 & 0.011 & 1.11 & 0.20 & Bal. \\
\hline
\end{tabular}

the components before welding. Especially, surfaces were polished with a \#300 emery paper and then cleaned with acetone.

Experiments were conducted on a $1 \mathrm{~kW} \mathrm{Nd:YAG} \mathrm{laser} \mathrm{materi-}$ als processing system with five-axis $\mathrm{CNC}$ working station. Fig. 2 shows the schematic diagram of laser overlap welding on dissimilar Ti6Al4V and 42CrMo sheets. The specimens were lapped and clamped on the fixture. $2.5 \mathrm{l} / \mathrm{min}$ flow of high purity argon gas was passed through the molten pool from top side to produce a shielding effect. The shielding gas could provide a protective environment for the sake of avoiding the reaction between the molten metal and ambient air and blow away plasma on the welded specimen surface.

Metallographic samples were prepared by electric discharge cutting, mechanical milling and grinding and were prepared using standard mechanical polishing procedures and etched in $\mathrm{HF}: \mathrm{HNO}_{3}: \mathrm{H}_{2} \mathrm{O}$ solution with volume ratio of $1: 2: 50$.

Microstructure of the welding seam was characterized by NephotII optical microscopy (OM), JSM-5800 scanning electron microscopy (SEM) equipped with LinkISIS S-530 energy dispersive spectrometer (EDS). A D/max-RB high power multi-crystal X-ray diffractometer (XRD) was used for phase identification. Microhardness along the transverse direction of the welded seam was measured by an automatic microhardness tester (HXD-1000B, Shanghai Optics Apparatus Ltd., China) with a test load of $0.98 \mathrm{~N}$ and a dwelling time of $15 \mathrm{~s}$.

\section{Results and discussion}

\subsection{Results of numerical simulation}

The FEM model was evaluated by comparing theoretical and experimental temperatures. Thermal couples were used to monitor temperature history of points A and B. Point A was at the bottom center of the lower sample. Point $B$ was located at the upper sheet surface and $4 \mathrm{~mm}$ away from the laser scanning line. It can be seen that the calculated temperature history at points A and B had a similar tendency to the experimental result, which reveals the rationality of the numerical model. The shielding gas nozzle moved together with the laser beam. When the shielding gas flew though the thermocouple, temperature reading at point $B$ might have been affected, what explains the difference between theoretical and experimental curves presented in Fig. 3(b).

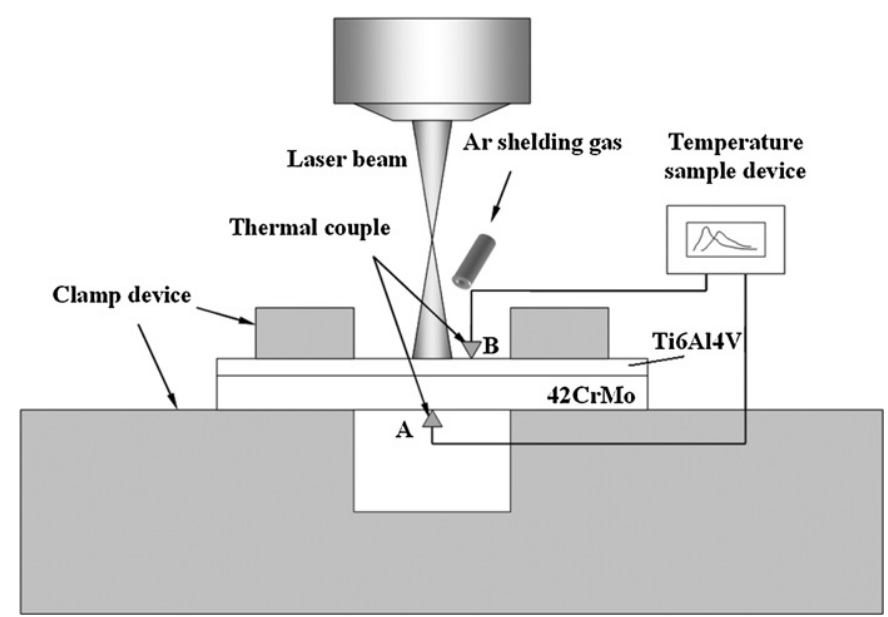

Fig. 2. Schematic diagram of laser overlap welding of Ti6Al4V and 42CrMo. 

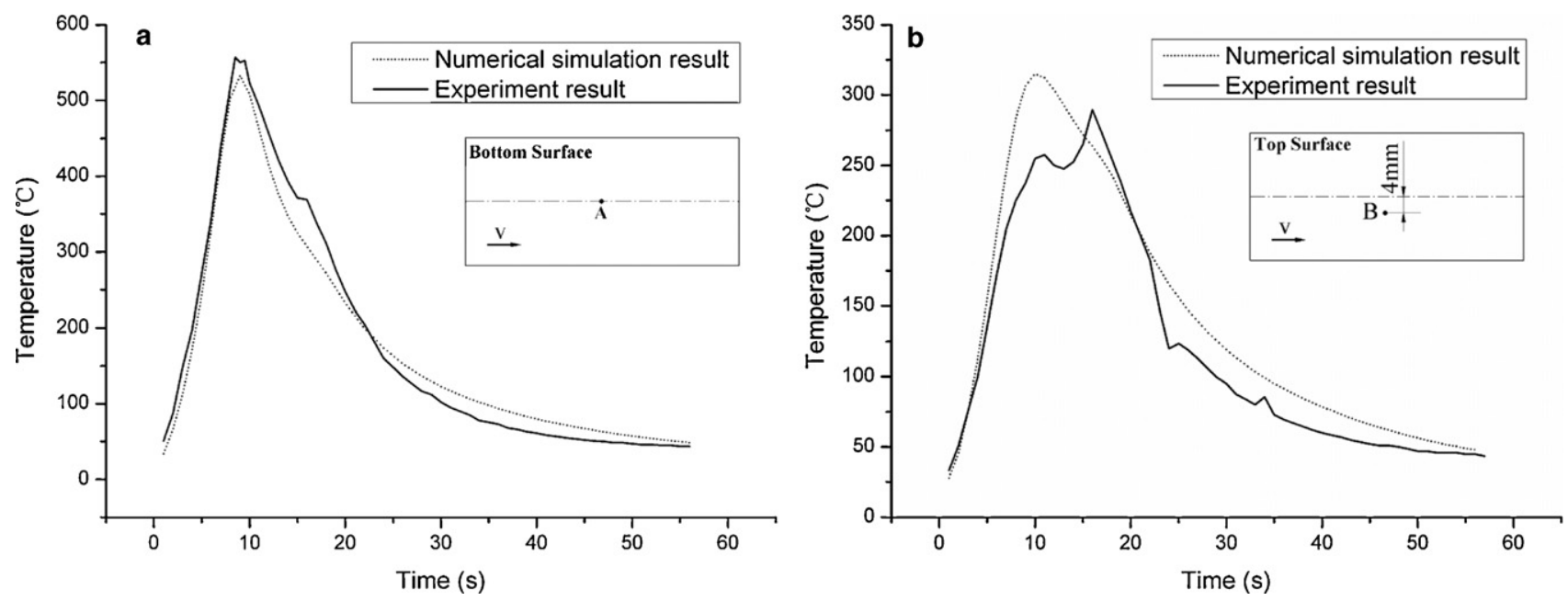

Fig. 3. Temperature history at the measuring points: (a) point A and (b) point B.

In order to reduce the diffusion of Ti and Fe elements at the interface during the welding process that could suppress the formation of Ti/Fe intermetallic compounds, the size of the molten pool at the interface must be controlled. The desired value of interface temperature was the melting point of lower sheet material 42CrMo $\left(1400^{\circ} \mathrm{C}\right)$. The vertical distance between $1400^{\circ} \mathrm{C}$ isotherm and top surface of the upper sheet was defined as welding depth, as shown in Fig. 4.

The calculated welding depth for different laser power values and scanning velocities is shown in Fig. 5. It could be seen that welding depth increased linearly with laser power at a constant scanning velocity. From the simulation results, the interface temperature reached or was a slightly higher than the melting point of $42 \mathrm{CrMo}$ (the welding depth reached $1 \mathrm{~mm}$ ) when power was $650 \mathrm{~W}$ or $700 \mathrm{~W}$, scanning velocity was $1 \mathrm{~mm} / \mathrm{s}$ and defocus distance was $-1 \mathrm{~mm}$.

Table 3 shows the experimental results with different process parameters. From the experimental investigation, joining occurred when laser power reached $650 \mathrm{~W}$ or $700 \mathrm{~W}$, scanning velocity was $1 \mathrm{~mm} / \mathrm{s}$ and defocus distance was $-1 \mathrm{~mm}$, however, joining did not occur under other groups of parameters. The experimental investigation results were in accordance with the simulation results shown in Fig. 5.

\subsection{Microstructure analysis of overlap welding joint}

Fig. 6 shows the macro morphology of weld cross-section. The upper material is Ti6Al4V and the lower material is 42CrMo.

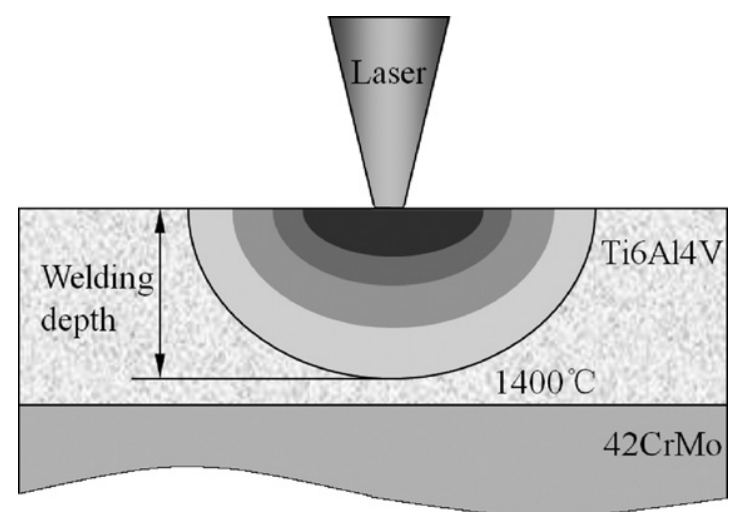

Fig. 4. Schematic representation of welding depth.

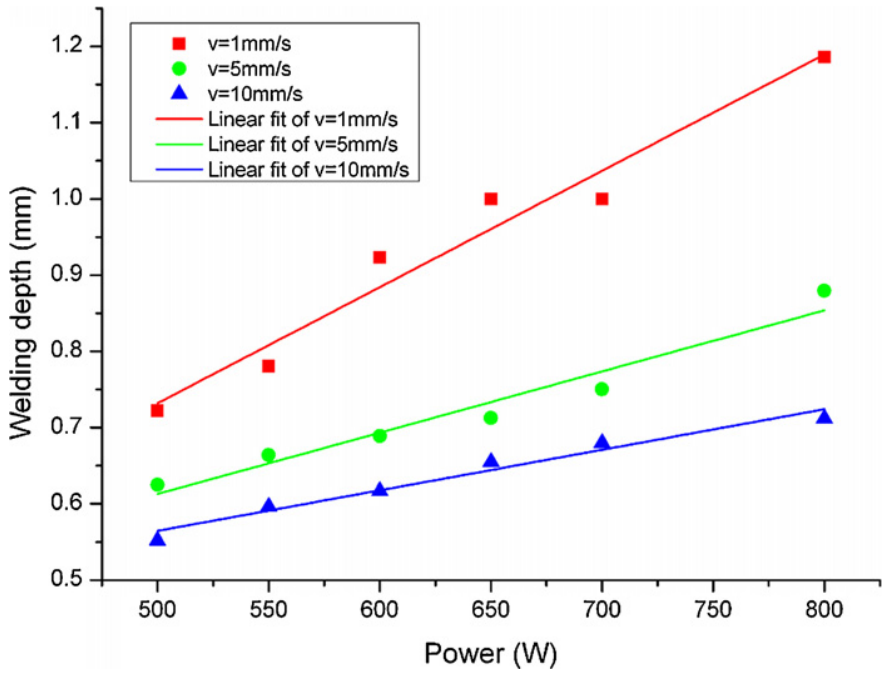

Fig. 5. Calculated welding depth as a function of laser power for different scanning velocities and $-1 \mathrm{~mm}$ defocus distance.

Ti6Al4V is a kind of $\alpha+\beta$ Titanium alloy. The crystal structure changes from $\alpha$ (hcp, hexagonal close-packed) to $\beta$ (bcc, bodycentered cubic) when the temperature exceeds to $995^{\circ} \mathrm{C}$. In the welding process, the base metal, the heat-affected zone (HAZ) and the fusion zone (FZ) experienced different thermal cycle which lead to different microstructures. The microstructure of Ti6Al4V parent metal shown in Fig. 7(a) consisted of two phases: inter-granular $\beta$ phase (black) in equiaxed $\alpha$ phase (white). Laser welding is

Table 3

Experimental results for different process parameters.

\begin{tabular}{llll}
\hline Power $(\mathrm{W})$ & $\begin{array}{l}\text { Scanning velocity } \\
(\mathrm{mm} / \mathrm{s})\end{array}$ & $\begin{array}{l}\text { Defocus distance } \\
(\mathrm{mm})\end{array}$ & Result description \\
\hline 210 & 40 & +3 & $\times$ \\
210 & 20 & +3 & $\times$ \\
210 & 5 & +3 & $\times$ \\
250 & 3 & -2 & $\times$ \\
500 & 1 & -1 & $\times$ \\
550 & 1 & -1 & $\times$ \\
600 & 1 & -1 & $\sqrt{ }$ \\
650 & 1 & -1 & $\times$ \\
650 & 2 & -1 & $\sqrt{ }$ \\
700 & 1 & -1 & $\times$ \\
700 & 2 & -1 & $\times$ \\
\hline
\end{tabular}

$\times$ : molten pool did not form at the interface; $\sqrt{ }$ : molten pool formed at the interface. 


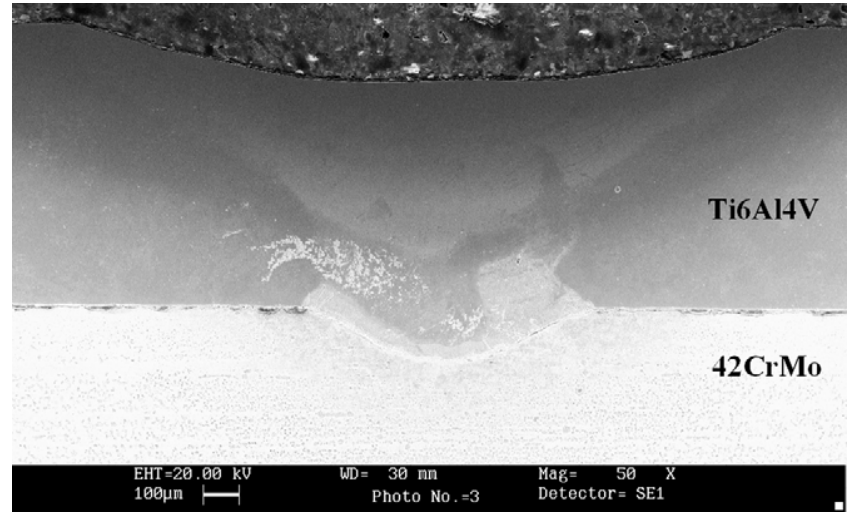

Fig. 6. Microstructure of the weld profile. (Power was $700 \mathrm{~W}$, scanning velocity was $1 \mathrm{~mm} / \mathrm{s}$, defocus distance was $-1 \mathrm{~mm}$.)

characterized by extremely high cooling rate (generally of the order $10^{4}{ }^{\circ} \mathrm{C} / \mathrm{s}$ against $10^{2}{ }^{\circ} \mathrm{C} / \mathrm{s}$ in GTA welding). Due to the rapid cooling ratio, there was no enough time for $\beta$ phase to transform to $\alpha$ balance phase by diffusion. As a result, the acicular structure formed through a regular process migration of atoms in $\beta$ phase at last. The microstructure of FZ of Ti6Al4V shown in Fig. 7(b) was composed of basket-like microstructure, namely acicular structure or widmanstatten structure. The chemical composition of $\mathrm{Ti}, \mathrm{Al}$, $\mathrm{V}$ and Fe are 92.33 at.\%, 4.83 at.\%, 2.52 at.\%, 0.32 at.\%, respectively. Fig. 7(c) shows the microstructure in the HAZ of Ti6Al4V. The HAZ near the fusion line contained a large number of acicular martensite due to the relatively high temperature in the thermal cycle process. However, for the HAZ far from the fusion line and close to the base material, since the maximum temperature was below the $\beta$ transition temperature, consequently, the phase transformation driving force was low and the amount of acicular martensite in this area was smaller. This phenomenon is similar to other results presented by Akman et al. (2009), in that case, the high cooling rates cause the formation of martensite in the weld zone.

Fig. 8(a) shows the OM micrographs of the base metal rolled $42 \mathrm{CrMo}$. As illustrated in the figure, the parent material was mixture of ferrite and pearlite. The material in the HAZ near the FZ side is shown in Fig. 8(b). Due to the high cooling rate, this region experienced a complete quenching process and formed needle-like martensite. The chemical composition of $\mathrm{Fe}, \mathrm{Cr}, \mathrm{Mn}, \mathrm{Mo}$, and $\mathrm{Si}$ in this region are 97.79 at.\%, 1.05 at.\%, 0.57 at.\%, 0.33 at.\%, 0.26 at.\%, respectively. Liu et al. (2007) found the similar microstructure features in laser penetration welding of superalloy $\mathrm{K} 418$ and 42CrMo steel. Fig. 8(c) shows the material in the HAZ away from the FZ. The material in this area was not fully quenched, so the microstructure in this area was a mixture of martensite and bainite.

\subsection{Chemical composition of interface}

At high magnifications, it can be seen from Fig. 9 that the microstructure in the interface zone consisted of two layers: a gray belt region (region $\mathrm{B}$ ) and a white belt region (region $\mathrm{C}$ ). The chemical composition of main elements, such as $\mathrm{Ti}, \mathrm{Al}$, and $\mathrm{Fe}$, were analyzed using EDS surface scan. Region A in Fig. 9 was enlarged and shown in Fig. 10. It can be seen that both iron and titanium elements were detected in the white belt region and gray belt region.

EDS analysis were carried out on regions B and C in Fig. 10 to evaluate their chemical composition. EDS spectra and chemical composition are shown in Fig. 11 and Table 4, respectively. As illustrated in the table, the region $\mathrm{B}$ contained predominantly $\mathrm{Ti}$ (67.75 at.\%) and Fe (24.08 at.\%). The content of Ti (53.79at.\%) and
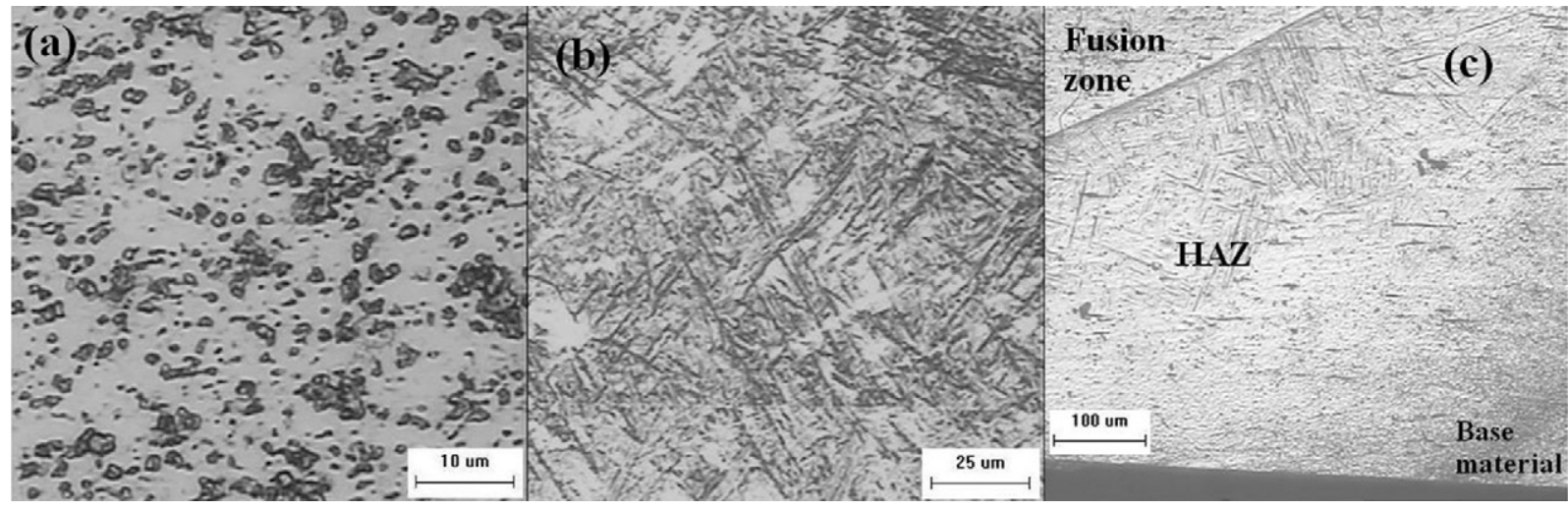

Fig. 7. Microstructure of Ti6Al4V (a), base material (b), and FZ (c) HAZ.

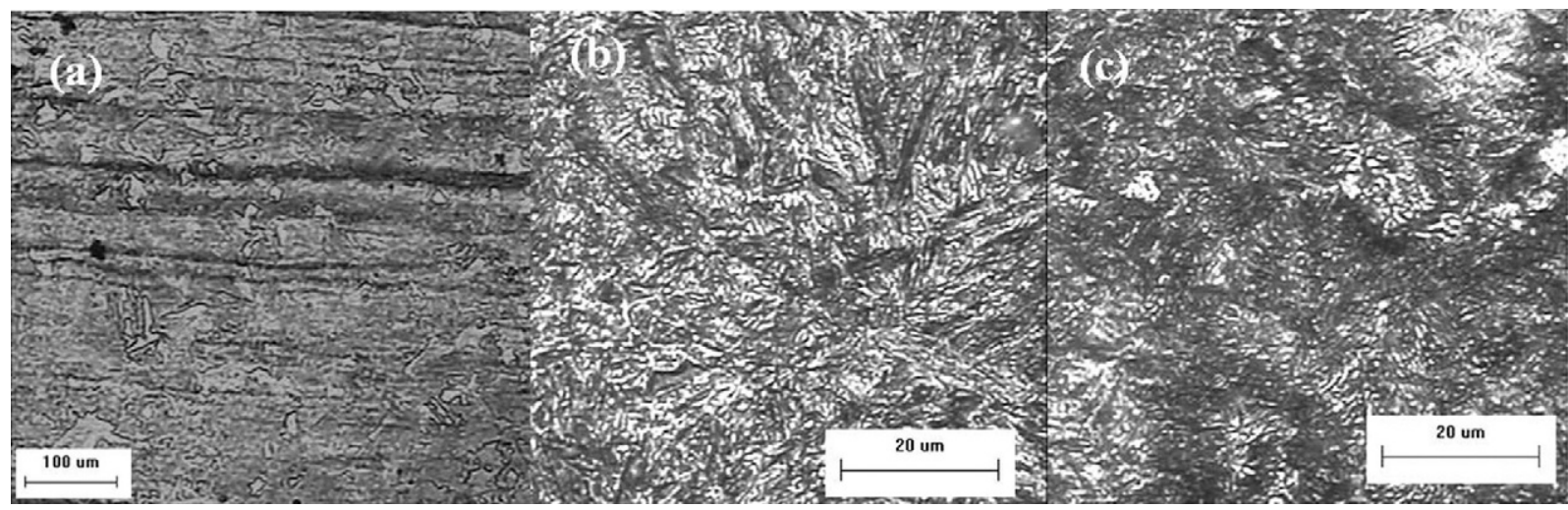

Fig. 8. Microstructure of $42 \mathrm{CrMo}$ (a), base material (b), and HAZ near FZ (c) HAZ far from FZ. 


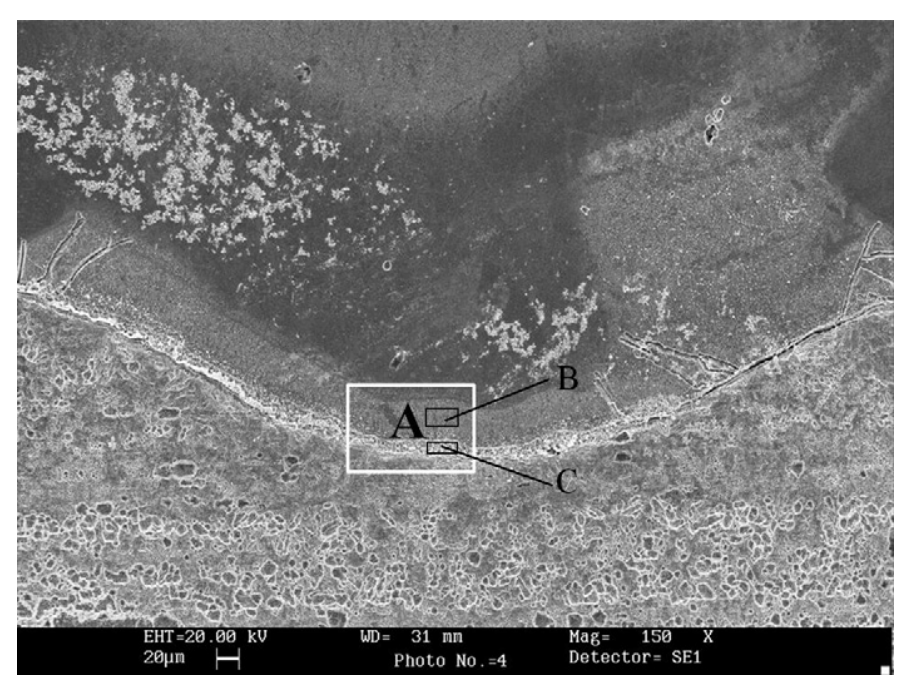

Fig. 9. SEM image of the interface of Ti6Al4V and 42CrMo.

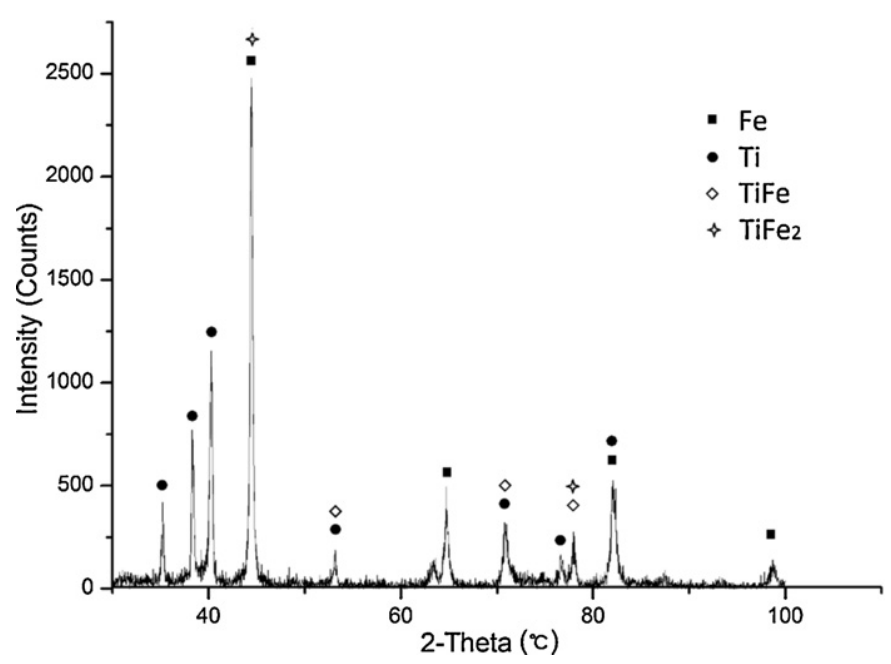

Fig. 12. XRD result of the laser welded seam.

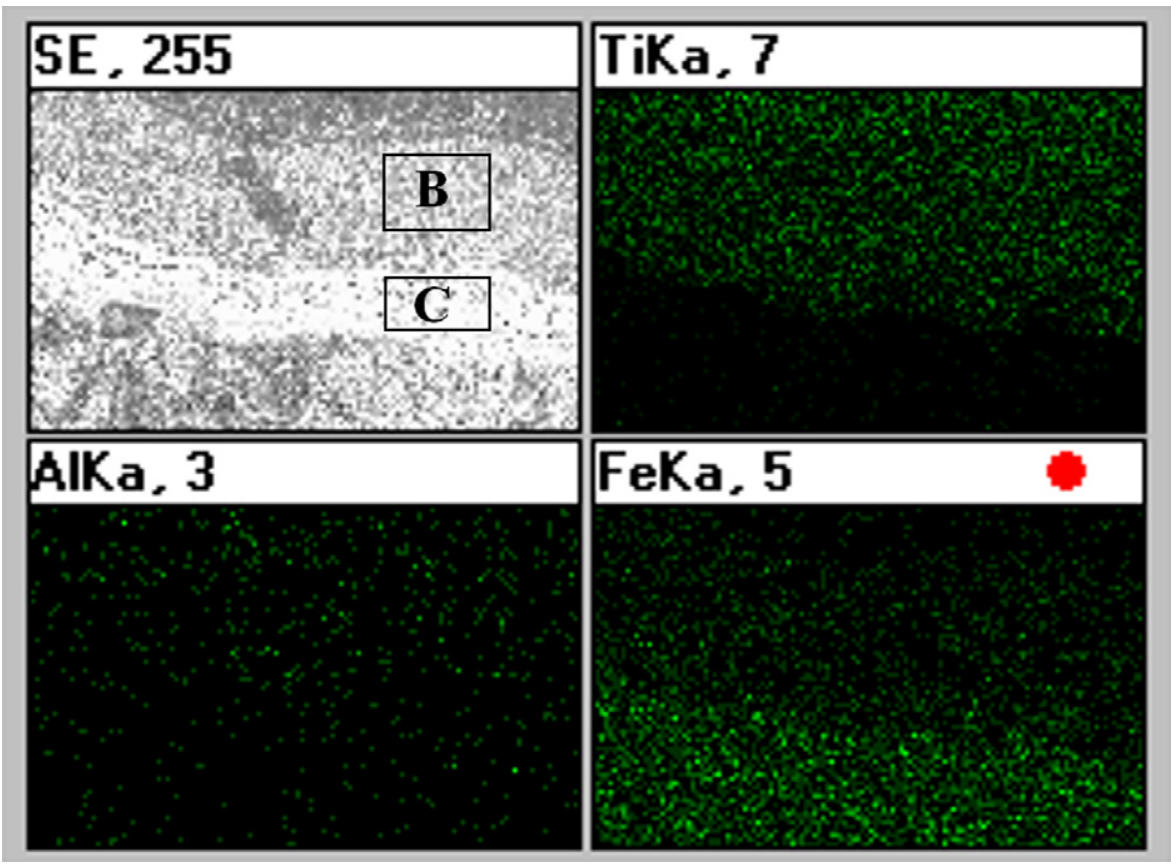

Fig. 10. Distributions of $\mathrm{Ti}, \mathrm{Al}$ and Fe elements in $\mathrm{FZ}$.
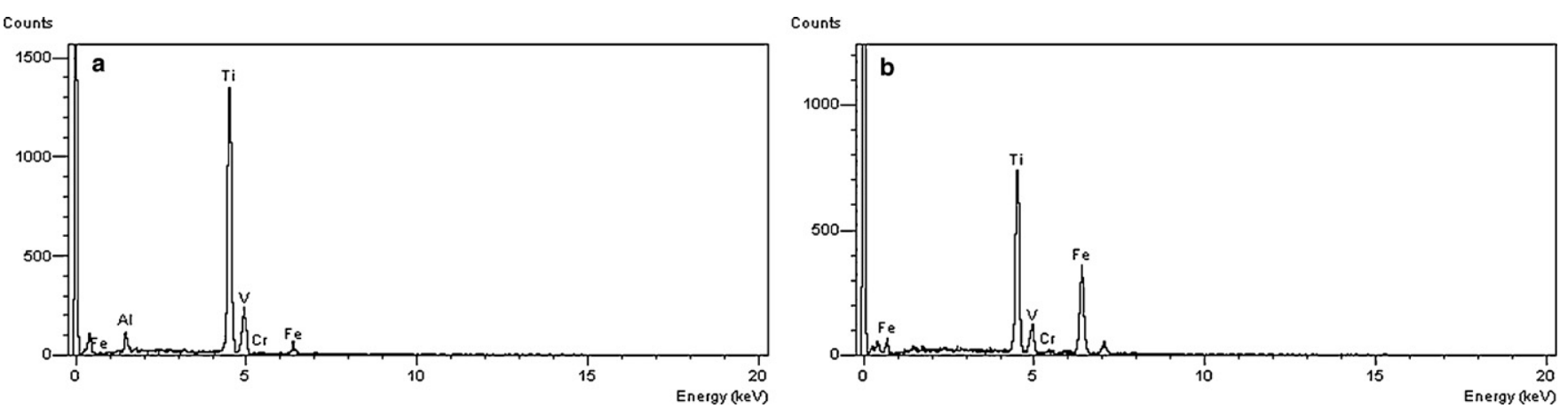

Fig. 11. EDS spectra of (a) region $B$ and (b) region $C$. 


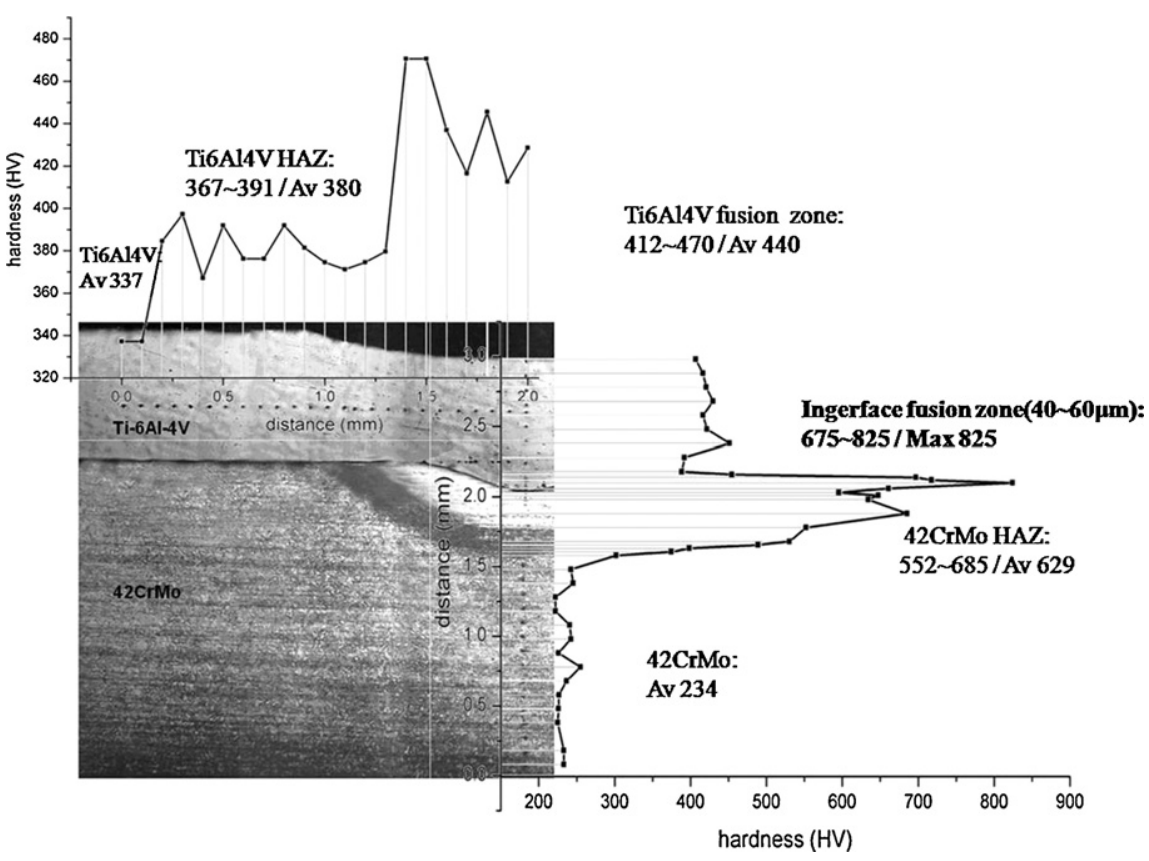

Fig. 13. Microhardness of the weld.

Fe (44.22 at.\%) elements in region C was approximately equal. The solubility of Fe in $\alpha$-Ti at room temperature is about $0.05-0.1 \%$. So the concentration of $\mathrm{Ti}$ and Fe has exceeded the solubility. Results indicated that the Ti/Fe intermetallic compounds may form at the interface during solidification.

The intermetallic compounds at the interface have been confirmed by X-ray diffraction technique, as presented in Fig. 12. The examination indicated the occurrence of $\mathrm{Ti} / \mathrm{Fe}$ intermetallic compounds $\mathrm{TiFe}, \mathrm{TiFe}_{2}$.

\subsection{Microhardness analysis of the overlap welding}

Fig. 13 shows the microhardness profiles of weld section along the depth (with applied load of $100 \mathrm{~g}$ ). For the upper sheet Ti6Al4V, the microhardness of weld zone was much higher compared to the HAZ and base metal due to the large content of acicular structure as result of the high rapid cooling rate. These variation tendencies were consistent with research data reported by Akman et al. (2009). In the lower sheet alloy steel $42 \mathrm{CrMo}$, the microhardness of HAZ was much higher than that of parent material mainly due to the self-quenching effects and the formation of a large amount of martensite. The microhardness of region A in Fig. 9 varied in the range of $675-825 \mathrm{HV}$, reaching the maximum values at the region near $42 \mathrm{CrMo}$. These results indicated that the intermetallic compounds might form at the interface of overlap sheets.

Table 4

EDS analysis results in regions of B and C (at.\%).

\begin{tabular}{lcc}
\hline Element & Region B & Region C \\
\hline $\mathrm{Ti}$ & 67.75 & 53.79 \\
$\mathrm{Al}$ & 4.83 & - \\
$\mathrm{V}$ & 2.52 & 1.28 \\
$\mathrm{Fe}$ & 24.08 & 44.22 \\
$\mathrm{Cr}$ & 0.82 & 0.71 \\
Total & 100.00 & 100.00 \\
\hline
\end{tabular}

Table 5

Thickness of intermetallic reaction layer for different power values, $1 \mathrm{~mm} / \mathrm{s}$ scanning velocity and $-1 \mathrm{~mm}$ defocus distance.

\begin{tabular}{lll}
\hline & \multicolumn{2}{l}{ Power $(\mathrm{W})$} \\
\cline { 2 - 3 } & 650 & 700 \\
\hline Thickness of white belt region $(\mu \mathrm{m})$ & 11 & 15 \\
Thickness of gray belt region $(\mu \mathrm{m})$ & 29 & 36 \\
Thickness of intermetallic reaction layer $(\mu \mathrm{m})$ & 40 & 51 \\
\hline
\end{tabular}

\subsection{Thickness of intermetallic reaction layer}

The formation of $\mathrm{Ti} / \mathrm{Fe}$ intermetallic compounds phase at the interface between Ti6Al4V and 42CrMo sheets was validated by EDS, XRD and microhardness testing. It could be seen through the microhardness testing that the gray and white intermetallic reaction layer had high hardness. Ghosh et al. (2005) found that the intermetallic compounds had an essential influence on the mechanical properties of the joint. Thickness of intermetallic reaction layer of the joint was measured and is shown in Table 5. From the result, it could be found that the thickness of intermetallic reaction layer increased with enhancing laser power at a constant scanning velocity. Kobayashi and Yakou (2002) has reported that joint strength increased with the reduction of reaction layer thickness. Therefore, the welded joint with better mechanical properties would be obtained by controlling the heat input and suppressing the growth of intermetallic reaction layer.

\section{Conclusions}

Laser overlap welding technique was used for joining titanium alloy and alloy steel, and further understanding of the welding process was achieved by FEM model calculation and experimental investigation. The following can be concluded from this work:

(1) The temperature history at measuring points obtained by FEM model considering the contact resistance and forced convection effect of the shielding gas flow has a qualitative agreement with the experimental observation. 
(2) Welding depth, a parameter defined to reflect the temperature field, increase linearly with laser power at a constant scanning velocity. The molten pool could just form at the interface by adjusting the process parameters according to the numerical simulation.

(3) Thickness of the intermetallic reaction layer containing $\mathrm{Ti} / \mathrm{Fe}$ intermetallic compounds could be decreased by reducing heat input. Therefore, there may be an optical heat input for the laser overlap welding and the formation of intermetallic compounds could be suppressed by optimizing process parameters during welding process.

\section{Acknowledgements}

The research was sponsored by National Natural Science of China (Grant No.10832011 and 10972222) and CAS Innovation Program.

\section{References}

Akman, E., Demir, A., Canel, T., Sinmazcelik, T., 2009. Laser welding of Ti6Al4V titanium alloys. J. Mater. Process. Technol. 209, 3705-3713.

Atasoy, E., Kahraman, N., 2008. Diffusion bonding of commercially pure titanium to low carbon steel using a silver interlayer. Mater. Charact. 59, 1481 1490.

Borrisutthekul, R., Yachi, T., Miyashita, Y., Mutoh, Y., 2007. Suppression of intermetallic reaction layer formation by controlling heat flow in dissimilar joining of steel and aluminum alloy. Mater. Sci. Eng. A 467, 108-113.

Chakraborty, N., Chakraborty, S., 2007. Modelling of turbulent molten pool convection in laser welding of a copper-nickel dissimilar couple. Int. J. Heat Mass transfer. 50, 1805-1822.

Fysikopoulos, A., Salonits, K., Chryssolouris, G., 2009. Energy efficiency of laser based manufacturing processes. In: James, S., Vojislav, K., Jovan, M. (Eds.), Proceedings of the ICALEO 2009-28th International Congress on Applications of Lasers and Electro-optics. Orlando, FL, USA, pp. 1525-1531.
Ghosh, M., Chatterjee, S., Mishra, B., 2003. The effect of intermetallics on the strength properties of diffusion bonds formed between Ti-5.5Al-2.4V and 304 stainless steel. Mater. Sci. Eng. A 363, 268-274.

Ghosh, M., Kundu, S., Chatterjee, S., Mishra, B., 2005. Influence of interface microstructure on the strength of the transition joint between Ti-6Al-4V and stainless steel. Metall. Mater. Trans. A. 36A, 1891-1899.

Hiraga, H., Fukatsu, K., Ogawa, K., Nakayama, M., Mutoh, Y., 2001. Nd:YAG laser welding of pure titanium to stainless steel. Quart. J. JWS. 19, 717-726.

Kahraman, N., Gulenc, B., Findik, F., 2005. Joining of titanium/stainless steel by explosive welding and effect on interface. J. Mater. Process. Technol. 169, 127-133.

Kobayashi, S., Yakou, T., 2002. Control of intermetallic compound layers at interface between steel and aluminum by diffusion-treatment. Mater. Sci. Eng. A 338, 44-53.

Kundu, S., Chatterjee, S., 2008. Characterization of diffusion bonded joint between titanium and 304 stainless steel using a Ni interlayer. Mater. Charact. 59, 631-637.

Kundu, S., Ghosh, A., Laik, A., Bhanumurthy, K., Kale, G.B., Chatterjee, S., 2005. Diffusion bonding of commercially pure titanium to 304 stainless steel using copper interlayer. Mater. Sci. Eng. A 407, 154-160.

Li, Y.L., He, P., Feng, J.C., 2006. Interface structure and mechanical properties of the $\mathrm{TiAl} / 42 \mathrm{CrMo}$ steel joint vacuum brazed with $\mathrm{Ag}-\mathrm{Cu} / \mathrm{Ti} / \mathrm{Ag}-\mathrm{Cu}$ filler metal. Scripta Mater. 55, 171-174.

Liu, X.B., Yu, G., Pang, M., Fan, J.W., Wang, H.H., Zheng, C.Y., 2007. Dissimilar autogenous full penetration welding of superalloy K418 and 42CrMo steel by a high power CWNd:YAG laser. Appl. Surf. Sci. 253, 7281-7289.

Lu, Y.F., 1993. Laser-induced temperature distribution in substrates with periodic multilayer structures. J. Appl. Phys. 74, 5761-5766.

Mazumder, J., Steen, W.M., 1980. Heat transfer model for CW laser material processing. J. Appl. Phys. 51, 941-947.

Phanikumar, G., Dutta, P., Chattopadhyay, K., 2001. Modelling of transport phenomena in laser welding of dissimilar metals. Int. J. Numer. Methods Heat Fluid Flow $11,156-171$.

Phanikumar, G., Dutta, P., Chattopadhyay, K., 2004. Computational modelling of laser welding of Cu-Ni dissimilar couple. Met. Trans. B 35B, 339-350.

Sheng, G.M., Huang, J.W., Qin, B., Zhou, B., Qiu, S.Y., Li, C., 2005. An experimental investigation of phase transformation superplastic diffusion bonding of titanium alloy to stainless steel. J. Mater. Sci. 40, 6385-6390.

Shiue, R.K., Wu, S.K., Shiue, J.Y., 2008. Infrared brazing of Ti-6Al-4V and 17-4 PH stainless steel with (Ni)/Cr barrier layer(s). Mater. Sci. Eng. A 488, 186-194.

Swift-Hook, D.T., Gick, A.E.F., 1973. Penetration welding with lasers. Weld. J. 52, 492-499. 